\title{
Differences in telomerase activity and the effects of AZT in aneuploid and euploid cells in colon cancer
}

\author{
XIAO FANG ${ }^{1 *}$, TENGHUI HU ${ }^{1,2,3^{*}}$, HUA YIN ${ }^{1}$, JUNJUN YANG ${ }^{1,2}$, WEIAN TANG ${ }^{1,2,3}$, \\ SIQI HU ${ }^{1,2,3}$ and XINGXIANG XU ${ }^{1,2}$ \\ ${ }^{1}$ Clinical Medical College, Yangzhou University; ${ }^{2}$ Department of Respiratory Medicine, Subei People's Hospital of \\ Yangzhou University, Yangzhou, Jiangsu 225001; ${ }^{3}$ Department of Respiratory Medicine, \\ The Second Affiliated Hospital of Xiangya, Central South University, Changsha, Hunan 410013, P.R. China
}

Received February 20, 2017; Accepted May 4, 2017

DOI: 10.3892/ijo.2017.4043

\begin{abstract}
Telomerase-targeted treatments for cancer have received a great deal of attention because telomerase is detected in nearly all cancer cells but is not expressed in most normal tissues. Aneuploidy refers to a chromosome number that is not a multiple of the base chromosome number and can indicate either hypo- or hyperploid chromosome numbers. Most solid tumors are aneuploid. In the present study, we sought to determine whether there are differences in telomerase activity and hTERT gene expression between aneuploid and euploid cells. Furthermore, we investigated telomerase inhibitor 3'-azido3'-deoxythymidine (AZT)-induced cell apoptosis using the p53-Puma/Noxa/Bax pathway and cell cycle arrest using the p53-p21 pathway in both aneuploid and euploid cells. Our results demonstrate that telomerase activity and hTERT gene expression were higher in aneuploid than in euploid cells. In addition, AZT exerted time- and dose-dependent cytotoxic effects on both aneuploid and euploid cells, and aneuploid cells were more sensitive to AZT-induced cytotoxicity. In addition, both the p53-Puma/Noxa/Bax pathway and the cell cycle arrest-associated p53-p21 pathway were involved in the AZT-induced suppression of tumor cells. Importantly, aneuploid cells were more sensitive to AZT-induced cell cycle arrest (p53-p21) and DNA double-strand breaks $(\gamma-\mathrm{H} 2 \mathrm{AX})$, while euploid cells were more sensitive to AZT-induced apoptosis (p53-Puma/Bax/Noxa).
\end{abstract}

\section{Introduction}

Telomeres are linear structures that are located at the end of eukaryotic chromosomes performing important functions

Correspondence to: Professor Xingxiang $\mathrm{Xu}$, Department of Respiratory Medicine, Subei People's Hospital of Yangzhou University, Yangzhou, Jiangsu 225001, P.R. China

E-mail:xuxx63@sina.com

${ }^{*}$ Contributed equally

Key words: telomerase, aneuploidy, AZT, apoptosis, proliferation during chromosome integration and stability $(1,2)$. In somatic cells, which lack telomerase, the length of a telomere is constantly being shortened by the process of cell replication. Telomerase, a ribonucleoprotein enzyme that is comprised of telomerase reverse transcriptase (hTERT) and an RNA subunit (TERC) in addition to other proteins that control telomerase activity to prevent telomere shortening $(3,4)$. It has been confirmed that hTERT overexpression plays a key role in the initiation of unlimited proliferation during oncogenesis and that introducing hTERT into epithelial cells and fibroblasts conferred infinite replicative potential (5-7). Moreover, overexpressing hTERT has been shown to be associated with advanced invasive tumor progression and worse prognoses (8-10). Currently available data demonstrate that $>90 \%$ of malignant tumors express high levels of telomerase activity, while normal and benign tissues do not with the exception of lymphoid cells, hematopoietic cells and germ cells, which possess proliferative potential $(11,12)$. These data indicate that telomerase might be useful as a molecular marker of tumors in a wide range of applications.

A primary phenotype of cancer is aneuploidy (13-16). Aneuploidy refers to any deviation from a normal number of chromosomes that results from a whole-chromosome gain or loss in a cell. Aneuploidy is generally caused by mitotic errors that occur as a result of a deficiency in one of the mechanisms, such as the spindle assembly checkpoint (SAC) (17-19), that are involved in ensuring that chromosomes segregate correctly. In humans, aneuploidy is harmful because it can cause some congenital malformation syndromes, spontaneous abortion and stillbirth. More than $90 \%$ of solid tumors and $50 \%$ of blood tumors are aneuploid (20). Although aneuploidy is observed in most human cancers, the functional roles of aneuploidy during tumor formation remain poorly understood. In mice and humans, a majority of autosomal trisomies and monosomies are detrimental to organismal survival (21), and it has been demonstrated that aneuploidy blocks cellular proliferation, spontaneous immortalization and survival (22). In contrast, because of its passive effects on cell immortalization and viability, aneuploidy is a hallmark of cancer cells (13). A recent bioinformatics analysis showed that the number of genes that can prompt tumorigenesis is higher than was previously thought and that aneuploidy may contribute 
to the development of the complexity of tumor genomics that affect multiple tumor-driving genes (23). Genetic studies performed using mouse models have provided experimentally based evidence showing that mutations in genes that regulate chromosome segregation initiate carcinogenesis by inducing the loss of heterozygosity (24). However, the influence of this loss on tumorigenesis is context-dependent, and aneuploidy was found to repress carcinogenesis in some mouse strains (25). Studies performed in yeast have identified genes that affect cell survival in the presence of aneuploidy. The survival factors associated with aneuploidy in human cells in addition to their functions in cancer formation remain to be determined. It was previously shown that the survival of aneuploid cells is limited by ATM/p53-dependent DNA damage checkpoints (26). Telomerase was found to function as an aneuploidy-associated survival factor that abrogated aneuploidy-induced DNA damage responses, premature senescence and cell depletion by alleviating telomere replication stress (27).

Telomerase-targeted therapies for tumors is receiving an increasing amount of attention, but substantial progress toward a clinical treatment involving telomerase has not been achieved. Azido-deoxythymidine (AZT) is a type of nucleoside analogue that is approved by the Food and Drug Administration to treat acquired immune deficiency syndrome (AIDS). AZT inhibits DNA double-strand formation by destroying the RNA reverse transcriptional ability of the virus, which results in the loss of the replication template and a consequential decrease in the replication rate (28-31). AZT has been shown to inhibit telomerase activity in a variety of cancer cells, including colon, human brain glioma and liver cancer cells (32-34).

It is clear that telomerase and aneuploidy play important roles in tumor development. In the present study, we demonstrate that telomerase activity and the expression of hTERT were higher in aneuploid than in euploid cells. In addition, we found that the telomerase inhibitor AZT inhibited cell proliferation and induced apoptosis and cell cycle arrest in both aneuploid and euploid cells via the downregulation of hTERT gene expression.

\section{Materials and methods}

Cell lines and lentiviral transduction. The human colorectal cancer cell line HCT116 was obtained from the Institute of Basic Medical Sciences, Subei Peoples' Hospital. To generate HCT116-shRNA-MAD2 cells, a short-hairpin RNA (shRNA) that targeted human MAD2 was cloned into the pInducer10MirRP lentiviral vector. The shRNA-containing plasmid was then packaged in lentiviral particles at the Vector Core. LentiPuroEMPTY-VSVG was used as the background control. A total of $1 \times 10^{6}$ cells $/ 10-\mathrm{cm}$ plate were transduced for $48 \mathrm{~h}$ with cell supernatant containing a lentivirus that was diluted in fresh serum-free medium at a ratio of $1: 1$. Stable cells were selected by incubating the cells with $10 \mu \mathrm{g} / \mathrm{ml}$ puromycin at $37^{\circ} \mathrm{C}$ for 3 weeks. The cells were maintained in Dulbecco's modified Eagle's medium (DMEM; Gibco, Carlsbad, CA, USA) supplemented with 10\% FBS (Sigma-Aldrich, St. Louis, MO, USA), $100 \mathrm{IU} / \mathrm{ml}$ penicillin-streptomycin and $2 \mu \mathrm{mM}$ L-glutamine at $37^{\circ} \mathrm{C}$ in a humidified atmosphere containing $5 \% \mathrm{CO}_{2}$.
The formation of aneuploidy. We used a doxycycline-induced program to conditionally knock down MAD2, resulting in HCT116-shRNA-MAD2 cells. The HCT116-shRNA-MAD2 cells were divided into two groups: one group was cultured in $0.2 \mu \mathrm{g} / \mathrm{ml}$ doxycycline-supplemented medium for $16 \mathrm{~h}$ (referred to as Dox (+) or aneuploid cells) to conditionally knock down MAD2 (HCT116-shRNA-MAD2 cells), and the other group was cultured in non-doxycycline medium and used as the control group (referred to as Dox (-) or euploid cells). HCT116 is a human colorectal cancer cell line that is chromosomal number-stable and has a near diploid karyotype.

Metaphase spreads. At 11 days after the doxycycline washout was performed, cells at 70 80\% confluency were treated with $80 \mathrm{ng} / \mathrm{ml}$ of the mitotic inhibitor nocodazole (SigmaAldrich) and $10 \mu \mathrm{M}$ of the protease inhibitor MG132 (Selleck Chemicals, Houston, TX, USA) and then incubated for $6 \mathrm{~h}$ at $37^{\circ} \mathrm{C}$. The cells were then treated with a hypotonic solution $(0.01 \mathrm{M}$ sodium citrate and $0.03 \mathrm{M} \mathrm{KCl})$ at $37^{\circ} \mathrm{C}$ for $15-20 \mathrm{~min}$ and fixed 3 times in Carnoy's fixative (methanol:acetic acid, 3:1) that was pre-cooled on ice. The cells were subsequently spread on glass slides that were pre-cooled at $-20^{\circ} \mathrm{C}$. Metaphase cells were stained using Giemsa (Beijing Solarbio Science and Technology Co., Ltd., Beijing, China), and chromosomes were counted under a fluorescence microscope for the chromosome counting analysis. Cells with any number of chromosomes other than 45 or 46 were defined as aneuploidy [the chromosome karyotype of the HCT116 cell line showed that the stem line chromosome number is near diploid with a modal number of $45(62 \%)$ and polyploid at $46(6.8 \%)$ according to the ATCC].

Western blot analysis. Total proteins were extracted using cell lysis buffer from cells placed on ice and then quantified using a Bradford protein assay. Equal amounts of cellular proteins $(60 \mu \mathrm{g})$ were separated using $10 \%$ sodium dodecyl sulfate (SDS)-PAGE according to the manufacturer's instructions (Beyotime Institute of Biotechnology, Shanghai, China). The resolved proteins were then transferred onto polyvinylidene difluoride (PVDF) membranes (Millipore, Billerica, MA, USA). The membranes were incubated in 5\% fat-free milk or 5\% BSA in $1 \mathrm{X}$ TBS containing $0.1 \%$ Tween-20 (TBST) at room temperature for $2 \mathrm{~h}$ and then probed with the following specific primary antibodies: MAD2L1, AF4005 (1:200, R\&D Systems, Minneapolis, MN, USA), $\alpha$-tubulin (1:2,000, Vazyme Biotech Co., Ltd., Nanjing, China), Puma, ABC158 (1:1,000; Millipore), Bax, AB2915 (1:1,500; Millipore), p21, MABE325 (1:1,000; Millipore), $\gamma$-H2AX, or 05-636, (1:400; Millipore) overnight at $4^{\circ} \mathrm{C}$. After the membranes were washed 3 times with 1X TBST, they were incubated with horseradish peroxidase (HRP)-conjugated secondary antibodies (1:3,000; Millipore) at room temperature for $90 \mathrm{~min}$. Reactive bands were visualized using a chemiluminescence detection system and analyzed using Image Lab software.

Telomerase activity. Telomerase activity of cells was quantified using a TeloTAGGG Telomerase PCR ELISA kit (Roche Diagnostics $\mathrm{GmbH}$, Mannheim, Germany) and a process called Telomeric Repeat Amplification Protocol (TRAP) based on the protocol described by Kim et al (35). A total of 
Table I. Primers used for PCR amplification.

\begin{tabular}{lll}
\hline Genes & \multicolumn{1}{c}{ Forward primer } & \multicolumn{1}{c}{ Reverse primer } \\
\hline GAPDH & 5'-CGTCTTCACCACCATGGAGA-3' & 5'-CGGCCATCGCCACAGTTT-3' \\
hTERT & 5'-AAGTTCCTGCACTGGCTGATG-3' & 5'-GCTTTGCAACTTGCTCCAGAC-3' \\
Bax & 5'-GGCAGCTGACATGTTTTCTGAC-3' & 5'-CACCCAACCACCCTGGTCTT-3' \\
Puma & 5'-GACCTCAACGCACAGTACGAG-3' & 5'-AGGAGTCCCATGATGAGATTGT-3' \\
Noxa & 5'-GTGTTCCTGTTGGGCGTTAC-3' & 5'-GGAGCATTTTCCGAACCTT-3' \\
p21 & 5'-CCTGTCACTGTCTTGTACCCT-3' & 5'-GCGTTTGGAGTGGTAGAAATCT-3'
\end{tabular}

$2.5 \times 10^{3}$ cells were harvested from each sample for the PCR reactions. The negative controls samples were heat-treated for $5 \mathrm{~min}$ at $95^{\circ} \mathrm{C}$ to inactivate telomerase activity. The positive control was provided by the kit. The following PCR program was run in a Thermal cycler: one cycle of $25^{\circ} \mathrm{C}$ for $20 \mathrm{~min}$ and $94^{\circ} \mathrm{C}$ for $5 \mathrm{~min}, 30$ cycles of $94^{\circ} \mathrm{C}$ for $30 \mathrm{sec}, 50^{\circ} \mathrm{C}$ for $30 \mathrm{sec}$, and $72^{\circ} \mathrm{C}$ for $90 \mathrm{sec}$ and one cycle of $72^{\circ} \mathrm{C}$ for $10 \mathrm{~min}$. The PCR products were subsequently analyzed using ELISA, and telomerase activity was obtained by determining the absorbance at $450 \mathrm{~nm}$ (with a reference wavelength of $690 \mathrm{~nm}$ ). The relative telomerase activities (RTA) of various samples were determined using the following formula: RTA $=[(\mathrm{AS}-\mathrm{AS}, 0) /$ AS,IS/]/[(ATS8-ATS8,0)/ATS8,IS] x 100, where AS, absorbance of the sample; AS, 0 , absorbance of the heat-treated sample; AS,IS, absorbance of the Internal Standard sample; ATS8, absorbance of the control template; ATS8,0, absorbance of the lysis buffer; and ATS8,IS, absorbance of the Internal Standard control template.

Cell viability measured by CCK- 8 assay. To investigate the effect of AZT (Sigma-Aldrich) on cell viability, both groups of cells were subjected to CCK-8 assays. Briefly, the cells were seeded in 96-well culture plates at $4 \times 10^{3}$ cells/well and treated with one of a variety of concentrations of AZT (i.e., 0, 100, $200,250,500$ or $1,000 \mu \mathrm{M}$ ) for one of the following incubation times: 24,48 and $72 \mathrm{~h}$. The cell suspension was then exchanged for fresh medium, and the cells were incubated with $10 \mu \mathrm{l}$ of CCK-8 solution (Invitrogen, Carlsbad, CA, USA) at $37^{\circ} \mathrm{C}$ for $4 \mathrm{~h}$. Absorbance was measured at $450 \mathrm{~nm}$ using an ELISA reader. All experiments were performed 3 times including 5 replicates for each sample.

Reverse transcription (RT)-PCR. Total RNA was extracted from cultured cells using TRIzol (Invitrogen). cDNA was obtained using an ABI7300 real-time PCR system with SYBRGreen PCR Master Mix (Vazyme Biotech). The primers used in these experiments are listed in Table I. The following cycling program was used: one cycle at $95^{\circ} \mathrm{C}$ for $5 \mathrm{~min}, 40$ cycles at $95^{\circ} \mathrm{C}$ for $10 \mathrm{sec}, 60^{\circ} \mathrm{C}$ for $30 \mathrm{sec}, 95^{\circ} \mathrm{C}$ for $15 \mathrm{sec}, 60^{\circ} \mathrm{C}$ for $60 \mathrm{sec}$ and $95^{\circ} \mathrm{C}$ for $15 \mathrm{sec}$. The samples were then held at $4^{\circ} \mathrm{C}$ until retrieved. The relative level of RNA was normalized to that of GAPDH using the $2^{-\Delta \Delta \mathrm{Ct}}$ method.

Data analysis. All statistical analyses were performed using SPSS 18.0 for Windows 10 (SPSS, Inc., Chicago, IL, USA). Two-way ANOVA with a Bonferroni post hoc test was used for multiple comparisons of two groups, as indicated. The

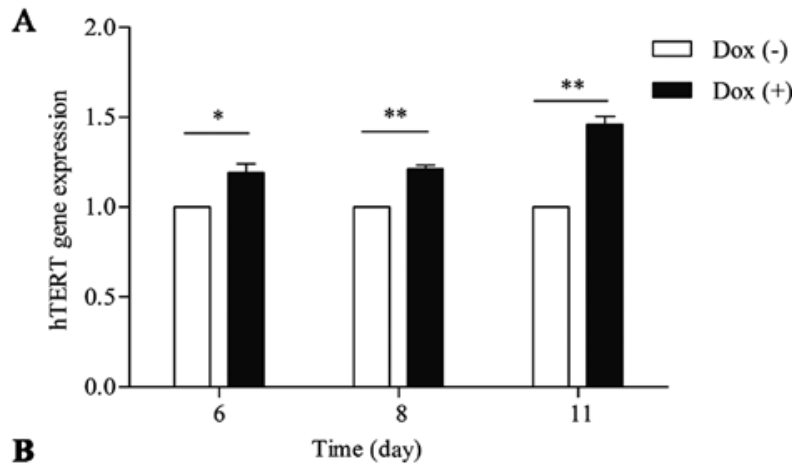

B

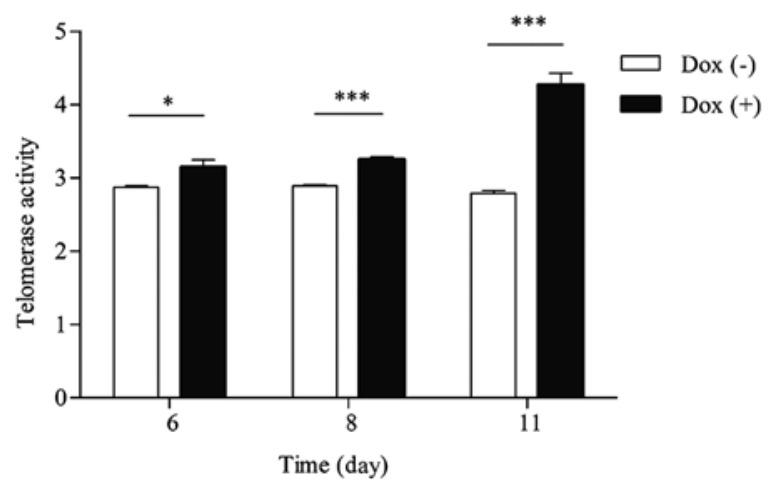

Figure 1. hTERT gene expression and telomerase activity in Dox (+) and Dox $(-)$ cells. (A) hTERT gene expression in Dox (+) and Dox (-) cells at 6,8 and 11 days after doxycycline washout (mean $\pm \mathrm{SD}, \mathrm{n}=3$ ). (B) Telomerase activity in Dox (+) and Dox (-) cells at 6,8 and 11 days after doxycycline washout (mean $\pm \mathrm{SD}, \mathrm{n}=3)\left({ }^{*} \mathrm{P}<0.05,{ }^{* *} \mathrm{P}<0.01\right.$ and ${ }^{* * *} \mathrm{P}<0.001$ relative to the Dox (-) cells).

expression of hTERT and telomerase activity were evaluated in the groups using two-tailed Student's t-tests. The data are represented as the mean \pm standard deviation of the mean. A $\mathrm{P}<0.05$ was defined as statistically significant.

\section{Results}

In aneuploid cells, hTERT gene expression and telomerase activity gradually increased after doxycycline washout. Telomerase regulation occurs mainly at the level of hTERT transcription. We sought to investigate the alterations in hTERT gene expression and telomerase activity that occurred in aneuploid cells in response to doxycycline washout. At 6 , 8 and 11 days after doxycycline washout, there was a gradual increase in hTERT gene expression and telomerase activity in aneuploid cells, and this increase peaked at 11 days after doxycycline washout $(1.46$-fold vs. euploid cells; $\mathrm{P}<0.05)$, as shown 
Table II. The karyotyping analysis of euploid and aneuploid group cells.

Chromosome numbers of indicated karyotype

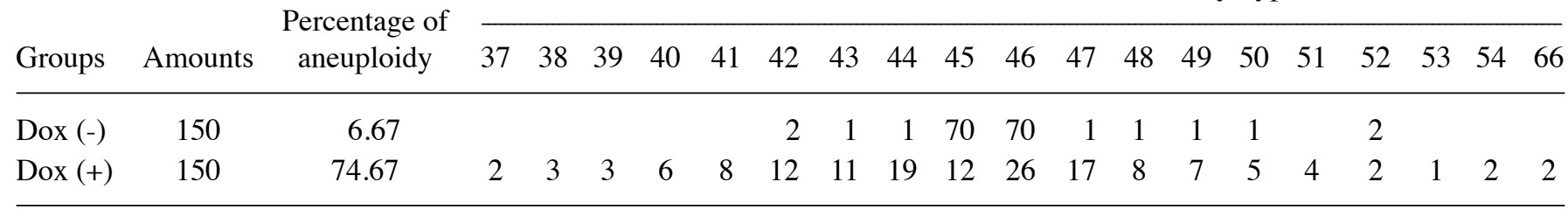
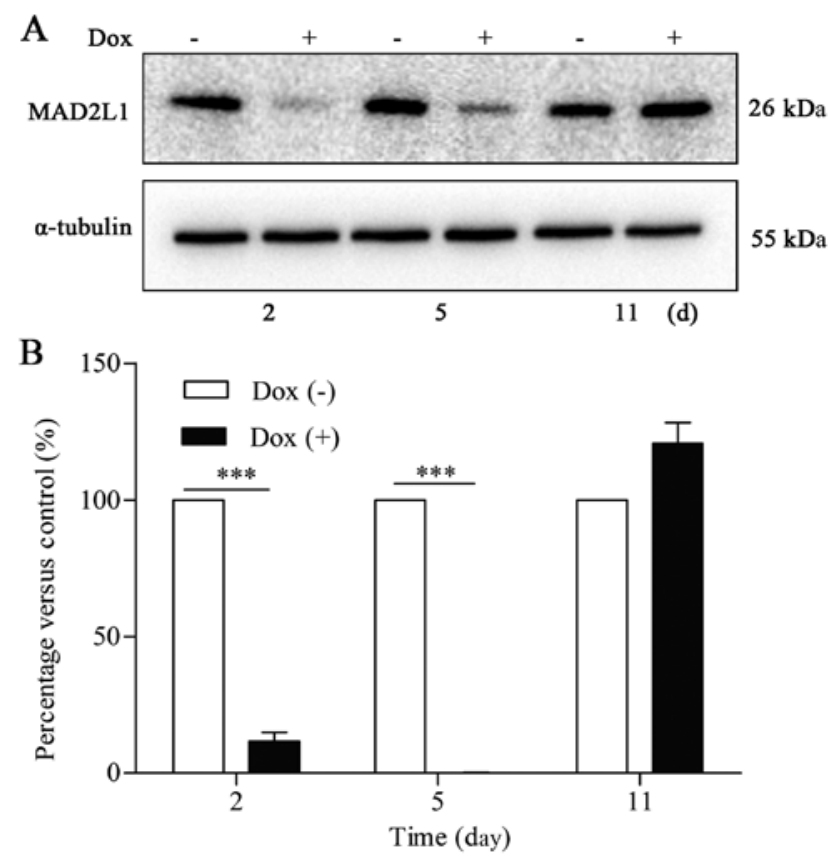

Figure 2. Western blot analysis of MAD2L1 expression. (A) Western blot analysis of MAD2L1 expression in Dox (+) and Dox (-) cells at 2, 5 and 11 days after doxycycline washout. (B) Quantitative analysis of MAD2L1 protein expression levels after normalization to $\alpha$-tubulin levels. The data are presented as the mean $\pm \mathrm{SD}(\mathrm{n}=3)\left({ }^{* * * *} \mathrm{P}<0.001\right.$ relative to the Dox $(-)$ cells $)$.

in Fig. 1A. Telomerase activity peaked at 11 days after doxycycline washout ( 2.79 vs. 4.26 in euploid and aneuploid cells, respectively; $\mathrm{P}<0.05$ ), as shown in Fig. 1B. Taken together, we found that hTERT gene expression and telomerase activity were higher in aneuploid cells than in euploid cells. Because we found that the differences in hTERT gene expression and telomerase activity between aneuploid and euploid cells were most obvious at 11 days, this time-point was used in the following tests.

The rate of aneuploidy following MAD2 knockdown. At 11 days after doxycycline washout, a karyotyping analysis of Dox (+) and Dox (-) groups was performed using metaphase spreads. As shown in Table II, the rate of aneuploidy was 112 out of 150 (74.67\%) in the Dox (+) group and 10 out of 150 (6.67\%) in the Dox (-) group. We next evaluated MAD2L1 protein expression in the Dox (+) and Dox (-) groups at 2, 5, and 11 days after doxycycline washout. Western blot analysis demonstrated that the protein level of MAD2L1 in aneuploid cells had decreased at day 2 , had gradually increased at day 5 , and had recovered to normal at day 11 after doxycycline washout. The fact that MAD2L1 protein levels had recovered to normal at day 11 after
A
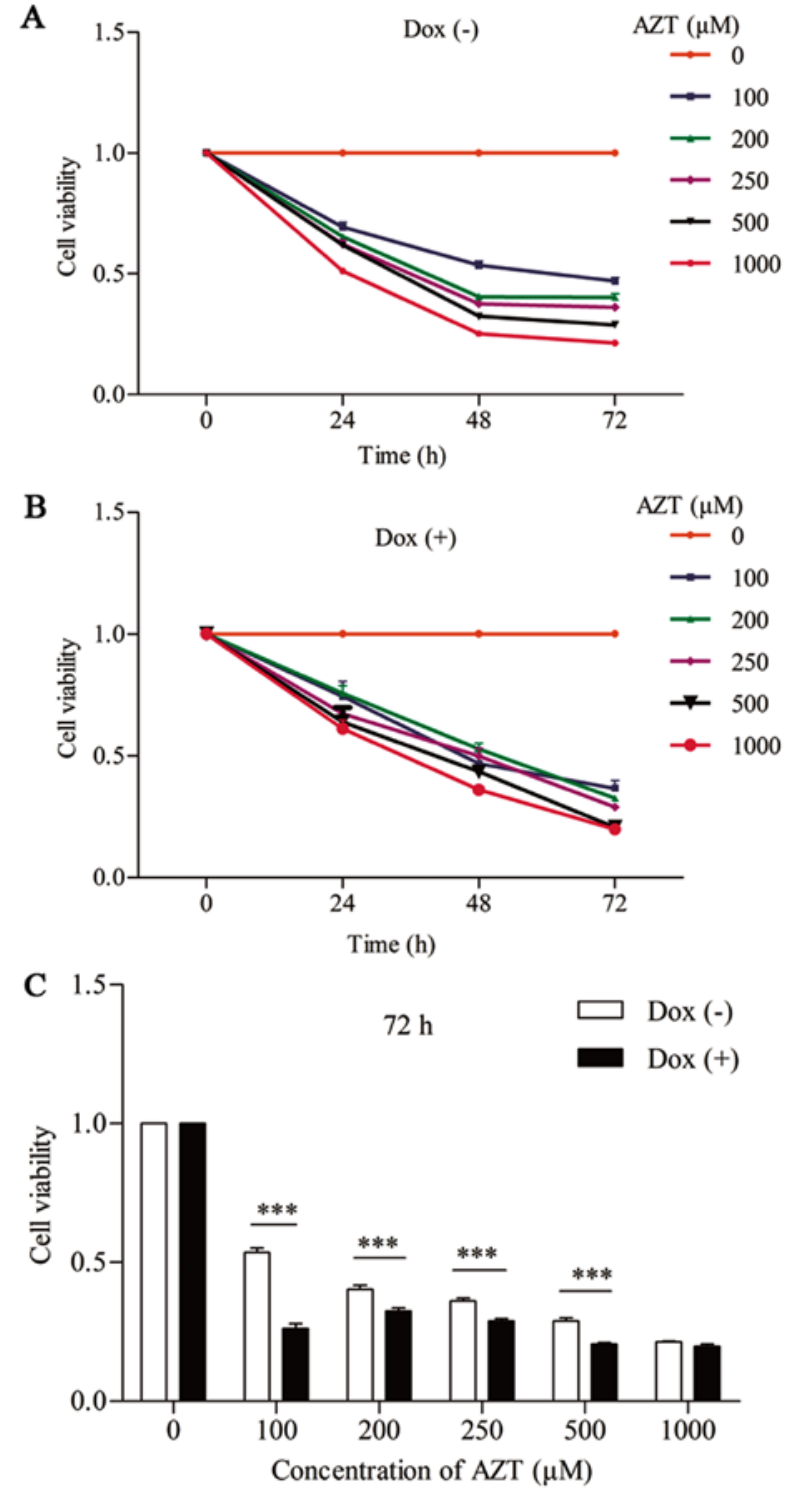

Figure 3. AZT inhibits cell proliferation in Dox (+) and Dox (-) cells. (A) Dox $(-)$ cells were exposed to different concentrations of AZT for different times $(24,48$ and $72 \mathrm{~h})($ mean $\pm \mathrm{SD}, \mathrm{n}=3)$. (B) Dox $(+)$ cells were treated with various concentrations of AZT for different times (24, 48 and $72 \mathrm{~h}$ ) (mean $\pm \mathrm{SD}$ $\mathrm{n}=3)$. (C) Cell viability in Dox $(+)$ and Dox (-) cells after exposure to AZT for $72 \mathrm{~h}$. Cell viability was lower in the Dox (+) group than in the Dox (-) group $\left({ }^{* * *} \mathrm{P}<0.001\right.$ compared to cells untreated with AZT).

washout demonstrated that Dox (+) cells are capable of proliferating at 11 days after doxycycline washout, as shown in Fig. 2.

AZT inhibits cell proliferation in Dox (+) and Dox (-) cells. The effect of different concentrations of AZT on cell viability 


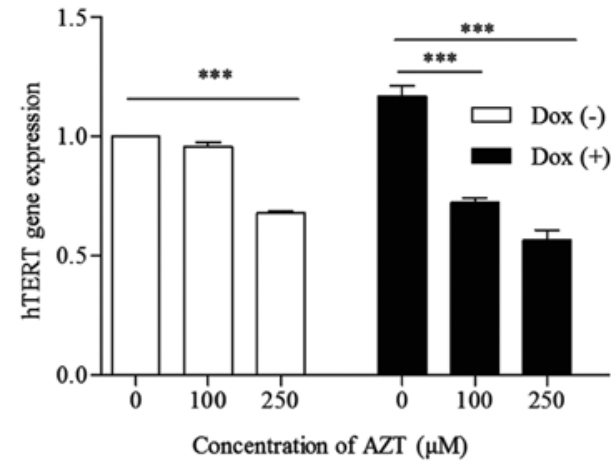

Figure 4. AZT downregulates the expression of hTERT gene in Dox (+) and Dox (-) cells. Dox (+) and Dox (-) cells were treated with 100 or $250 \mu \mathrm{M}$ AZT for $72 \mathrm{~h}$. hTERT gene expression was subsequently analyzed using RT-PCR. One representative result among three independent tests is shown $(n=3$; ${ }^{* * *} \mathrm{P}<0.001$ compared to cells untreated with AZT).

in Dox (+) and Dox (-) cells was determined using CCK-8 assays. As shown in Fig. 3A and B, viability was substantially decreased in a dose- and time-dependent manner in Dox (+) and Dox (-) cells following exposure to AZT. As shown in Fig. 3C, the cytotoxic impact of AZT was concentrationdependent. Cell viability was decreased by $\sim 53,60,64,71$ and $79 \%$ in Dox (-) cells and by $24,68,71,79$ and $80 \%$ in Dox (+) cells after $72 \mathrm{~h}$ of exposure to $100,200,250,500$ or $1,000 \mu \mathrm{M}$ of AZT, respectively. The rate of reduction in cell viability was therefore higher in Dox (+) cells than in Dox (-) cells. These data indicate that the Dox (+) cells were more sensitive to the cytotoxic impact of AZT than the Dox (-) cells.

AZT downregulates the expression of hTERT in Dox (+) and Dox (-) cells. Telomerase is regulated mainly by the level of hTERT transcription. As shown in Fig. 4, there was a significant decrease in hTERT gene expression following $72 \mathrm{~h}$ of treatment with 100 or $250 \mu \mathrm{M}$ AZT in both the Dox $(+)$ and Dox (-) cells. This change in hTERT gene expression was concentration-dependent and decreased by $\sim 5$ and $32 \%$ in the Dox (-) cells and $\sim 38.46$ and $51.28 \%$ in the Dox (+) cells, respectively. The rate of reduction in hTERT gene expression was higher in the Dox (+) cells than in the Dox (-) cells $(\mathrm{P}<0.05)$, indicating that the Dox $(+)$ cells were more sensitive to AZT than the Dox (-) cells.

Effects of AZT on the roles of Puma, Bax, Noxa and p21 in Dox (+) and Dox (-) cells. To determine the effect of AZT on apoptosis in the two groups of cells, we first used RT-PCR to detect the mRNA expression levels of p53-targeted genes (Puma, Bax, Noxa and p21). We found that these genes were positively regulated by 553 and played pro-apoptotic roles. The mRNA levels of these genes were upregulated in a dosedependent manner following exposure to 100 or $250 \mathrm{M}$ AZT for $72 \mathrm{~h}$, as shown in Fig. 5. The levels of Puma, Bax and Noxa gene expression following exposure to 0,100 and $250 \mu \mathrm{M} \mathrm{AZT}$ were 1:2.68:3.49, 1:1.89:2.22 and 1:2.34:2.44, respectively in the Dox (-) cells and 1:1.94:2.01, 1:1.54:1.85 and 1:1.42:1.97, respectively, in the Dox (+) cells, and the differences between the responses of the two groups of cells were significantly different $(\mathrm{P}<0.05)$. The level of $\mathrm{p} 21$ gene expression following exposure to 0,100 and $250 \mu \mathrm{M}$ AZT for $72 \mathrm{~h}$ was 1:3.38:4.91
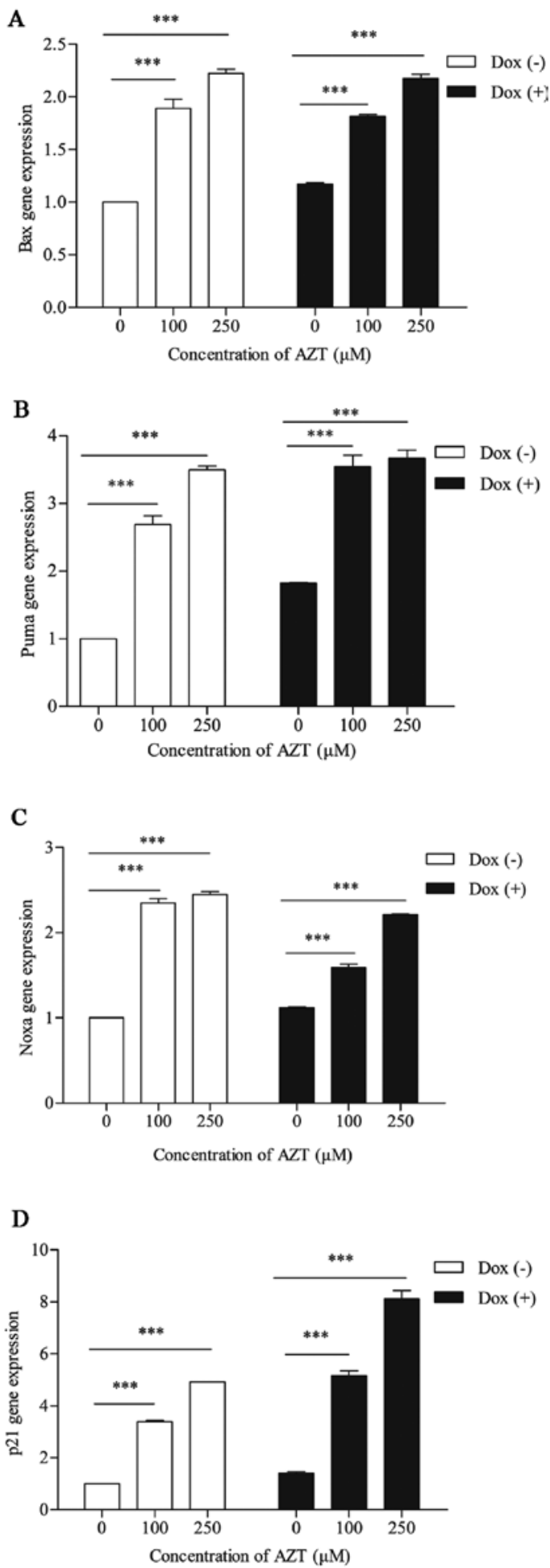

Figure 5. AZT upregulates the expression of Puma, Bax, Noxa and p21 in Dox (+) and Dox (-) cells. (A) Bax gene expression in Dox (+) and Dox (-) cells that were treated with 100 or $250 \mu \mathrm{M}$ AZT for $72 \mathrm{~h}$. (B) Puma gene expression Dox (+) and Dox (-) cells that were treated with 100 or $250 \mu \mathrm{M}$ AZT for $72 \mathrm{~h}$. (C) Noxa gene expression in Dox (+) and Dox (-) cells that were treated with 100 or $250 \mu \mathrm{M}$ AZT for $72 \mathrm{~h}$. (D) p21 gene expression in Dox $(+)$ and Dox (-) cells that were treated with 100 or $250 \mu \mathrm{M}$ AZT for $72 \mathrm{~h}$. One representative result from three independent tests is shown $\left(\mathrm{n}=3 ;{ }^{* * *} \mathrm{P}<0.001\right.$ compared to cells untreated with AZT).

in the Dox (-) cells and 1:3.67:5.78 in the Dox (+) cells, and the differences in the responses of the two lines of cells were significantly different $(\mathrm{P}<0.05)$. These data indicate that the 
A

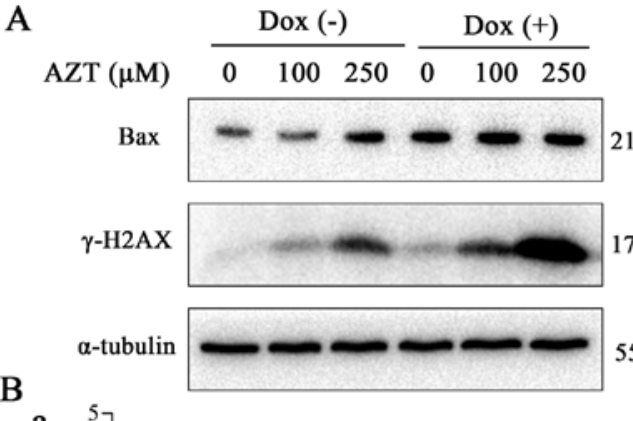

a

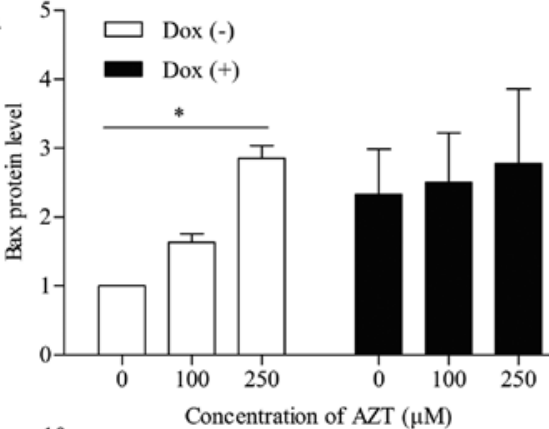

c

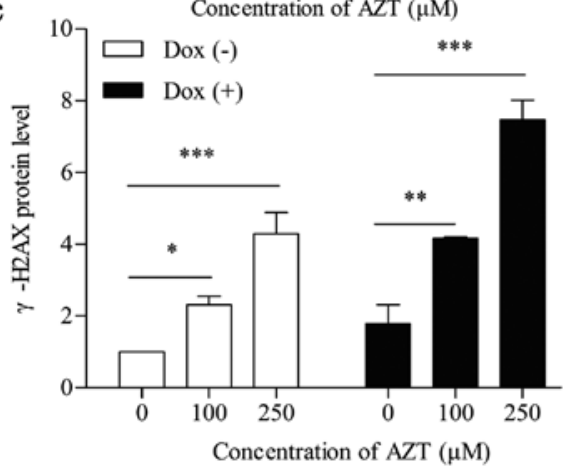

$\operatorname{AZT}(\mu \mathrm{M}) \quad \frac{\operatorname{Dox}(-)}{0} \quad \frac{}{100} \quad \frac{250}{0} \quad \begin{array}{lll}\text { Dox }(+) \\ 0\end{array}$

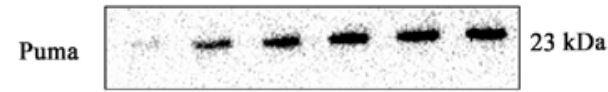

$17 \mathrm{kDa}$

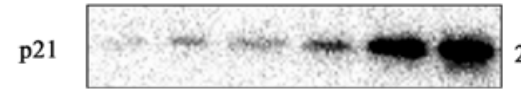

$21 \mathrm{kDa}$
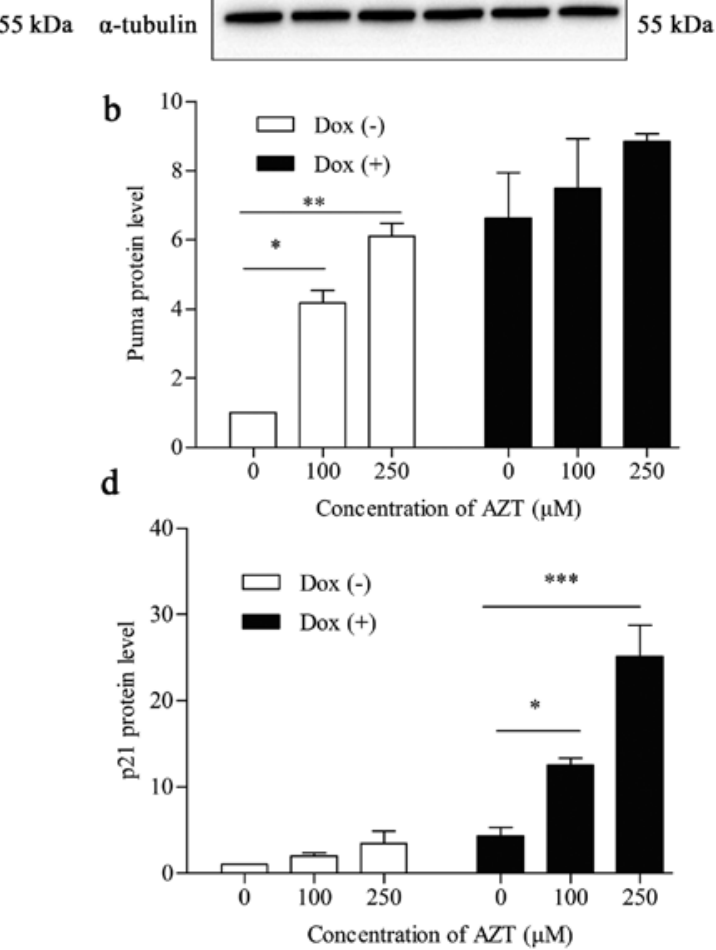

Figure 6. The protein levels of Puma, Bax, p21 and $\gamma$-H2AX in the two groups of cells. (A) Western blot analysis of Puma, Bax, p21 and $\gamma$-H2AX expression in Dox (+) and Dox (-) cells that were treated with 100 or $250 \mu \mathrm{M}$ AZT for $72 \mathrm{~h}$. (B) Quantification of Puma, Bax, p21 and $\gamma$-H2AX protein expression levels following normalization to $\alpha$-tubulin levels. The data are presented as the mean $\pm \mathrm{SD}\left({ }^{*} \mathrm{P}<0.05,{ }^{* * *} \mathrm{P}<0.01\right.$ and ${ }^{* * * *} \mathrm{P}<0.001$ compared to cells untreated with $\left.\mathrm{AZT}\right)$.

euploid cells were more sensitive than the aneuploid cells to the induction of the p53-Puma/Bax/Noxa pathways during AZT-induced apoptosis and that the aneuploid cells were more sensitive than the euploid cells to the induction of the p53-p21 pathways during AZT-induced cell cycle arrest.

Effects of AZT on the roles of the Puma, Bax, p21 and $\gamma-H 2 A X$ proteins in aneuploid and euploid cells. Puma proteins are pro-apoptotic participants in the Bcl-2 family that could impact the levels of apoptosis-related proteins (36). Cell cycle arrest occurs in G1 phase when the p53-p21-cip1 pathway is activated (37). The phosphorylation of the $\mathrm{H} 2 \mathrm{AX}$ histone ( $\gamma-\mathrm{H} 2 \mathrm{AX}$, phosphorylated histone $\mathrm{H} 2 \mathrm{AX}$ on serine 139) is an early indicator of DNA double-strand breaks (DSBs). We therefore determined the protein level of the pro-apoptosis proteins Puma and Bax, the cell cycle-arrest protein p21, and the DNA double-strand break protein $\gamma$-H2AX using western blot analysis. As shown in Fig. 6, the Puma, Bax, p21 and $\gamma-\mathrm{H} 2 \mathrm{AX}$ proteins were upregulated in a dose-dependent manner following exposure to 100 and $250 \mu \mathrm{M}$ AZT for $72 \mathrm{~h}$ in the Dox (-) cells. In the Dox (+) cells, p21 and $\gamma-\mathrm{H} 2 \mathrm{AX}$ were upregulated in a dose-dependent manner following exposure to 100 and $250 \mu \mathrm{M}$ AZT for $72 \mathrm{~h}$. However, Puma and Bax levels were not altered. The relative protein levels of p21 and $\gamma-\mathrm{H} 2 \mathrm{AX}$ in cells exposed to 0,100 and $250 \mu \mathrm{M}$ AZT were 1:2.23:3.94 and 1:1.97:3.43 in the Dox (-) cells and 1:2.93:5.32 and 1:3.02:5.91 in the Dox (+) cells, respectively. There was a significant difference in the levels of the p21 and $\gamma-\mathrm{H} 2 \mathrm{AX}$ proteins between the two groups of cells following exposure to 0,100 and $250 \mu \mathrm{M}$ AZT $(\mathrm{P}<0.05)$. AZT upregulated the level of Puma, Bax, p21 and $\gamma-\mathrm{H} 2 \mathrm{AX}$ in the Dox (-) cells and upregulated the levels of p21 and $\gamma-\mathrm{H} 2 \mathrm{AX}$ in the Dox (+) cells. Collectively, these findings demonstrate that the aneuploid cells were more sensitive than the euploid cells to AZT-induced cell cycle arrest (indicated by p53-p21 levels) and DNA doublestrand breaks (indicated by $\gamma$-H2AX levels), whereas euploid cells were more sensitive than aneuploid cells to AZT-induced apoptosis (indicated by p53-Puma/Bax/Noxa levels).

\section{Discussion}

The relationship between aneuploidy and tumorigenesis has long been recognized (38). Some authors have suggested that aneuploidy simply represents a side-effect of the course of tumor formation, while others have argued that aneuploidy is associated with oncogenic transformation. Studies of 


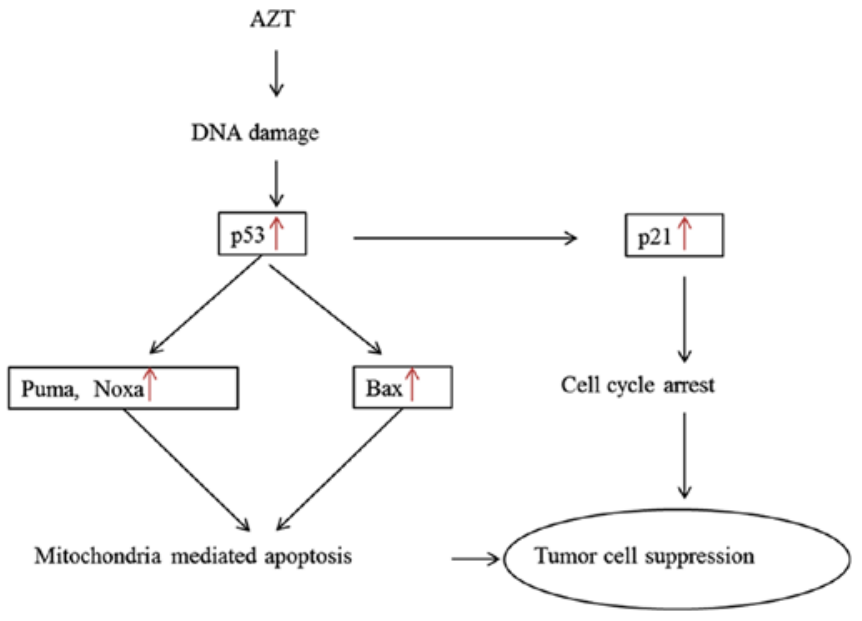

Figure 7. A model demonstrating that p53 and its downstream genes are correlated with the AZT induced suppression of tumor cells.

certain aneuploidy karyotypes performed in mouse models of chromosomal instability have suggested that aneuploidy can either promote or inhibit tumorigenesis. Mouse trisomy for chromosome 16 is resistant to adenomatous polyposis coli (APC)-induced colon cancer (39). Humans with chromosome 21 trisomy are less likely to develop tumors than euploid individuals (40). In contrast, trisomy 8 appears to increase the risk of hematopoietic malignancies. In total, $5 \%$ of all cases of acute lymphoblastic leukemia (ALL), 10-15\% of all cases of acute myeloid leukemia (AML) and $25 \%$ of all cases of chronic myeloid leukemia (CML) have an extra copy of chromosome $8(39,41)$. It has been suggested that a low frequency of chromosome mis-segregation accelerates tumorigenesis by increasing the likelihood of producing a tumorigenesis-promoting karyotype. When the rate of chromosome mis-segregation is too high, tumor cells cannot survive with these types of tumorpromoting karyotypes. Instead, cells with inviable karyotypes are constantly produced, resulting in cell death and, consequentially, tumor repression (42).

Chromosome mis-segregation can lead to aneuploidy. The currently available data suggest that a series of biochemical pathways enable the faithful segregation of sister chromosomes, and malfunctions in these pathways can cause chromosomal mis-segregation, for example, by disrupting the spindle assembly checkpoint, inducing centrosome abnormalities, altering microtubule-kinetochore dynamics, or causing defects in chromosome cohesion (17). Short hairpin RNAs (shRNAs) against GJB3, RXFP1, OSBPL3 and STARD9 were introduced into BJ and IMR90 fibroblast cell lines as per Meena et al to induce aneuploidy (27). These 4 candidate genes are directly associated with ploidy-affecting pathways (27). For example, Li et al (26) knocked down MAD2L1 using siRNA to produce aneuploidy. In the present study, we used a MAD21-targeting shRNA to generate an inducible expression system that was triggered by doxycycline. MAD2L1 is a component of the SAC that is necessary for proper sister chromatid segregation. Defects in MAD2L1 can cause chromosome mis-segregation, leading to the formation of aneuploidy (17).

p53 is well-known for its role as the guardian of the genome. It also plays a pivotal role in suppressing tumorigenesis (43). Our experimental data demonstrate that two p53-dependent pathways play pivotal roles in this process, as shown in Fig. 7. We first showed that the DNA damage caused by AZT in aneuploid and euploid cells is capable of inducing the expression of the p53-Puma/Bax/Noxa pathways, ultimately leading to cellular apoptosis. Second, p21 is widely accepted as a transcriptional target of p53. Our data clearly indicate that the p53-p21 pathway is linked to AZT-induced cell cycle arrest. We found that aneuploid cells were more sensitive to AZT-induced cell cycle arrest (p53-p21) and DNA double-strand breaks $(\gamma-\mathrm{H} 2 \mathrm{AX})$, while euploid cells were more sensitive to AZT-induced apoptosis (p53-Puma/Bax/Noxa). It has previously been shown that aneuploidy plays dual roles in promoting or inhibiting the process of tumor formation and that specific aneuploidy karyotypes promote tumorigenesis. A doxycycline strategy was utilized to disrupt SAC function and therefore trigger aneuploidy in cells. Aneuploid cells exhibited a high rate of early cell death but recovered after 11 days, before exposure to AZT. During this early period, the aneuploid cells that were unfit for survival were induced to undergo death, while those that survived aneuploidy were likely to undergo tumorigenesis as a result of gaining a specific chromosome karyotype that made them resistant to AZT-induced apoptosis. Hence, the euploid cells were more sensitive to AZT-induced apoptosis (p53-Puma/ Bax/Noxa). Our data show that Puma and Bax gene expression are correlated with relevant protein expression levels in euploid cells but not in aneuploid cells. Whether the process of translation is disrupted or the apoptotic pathway differs between aneuploid and euploid cells remains unknown.

Taken together, our data indicate that hTERT gene expression and telomerase activity are higher in aneuploid cells than in euploid cells. Both apoptosis (indicated by the p53-Puma/ Bax/Noxa pathway) and cell cycle arrest (indicated by the p53-p21 pathway) were involved in AZT-induced cell death in both aneuploid and euploid cells. The apoptotic pathway in aneuploid cells requires additional study.

\section{Acknowledgements}

The present study was supported by the National Natural Science Funds (81302016), the Clinical Medicine Science and Technology Projects of Jiangsu Province (BL2012054) in China, the National Natural Science Foundation of China (81402484), Jiangsu Provincial Natural Science Foundation (BK20140497), the Natural Science Fund for Colleges and Universities in Jiangsu Province (14KJB310024), Jiangsu Provincial Medical Youth Talent Program (QNRC2016322), and Yangzhou Municipal Natural Science Foundation (YZ2014059). We thank Dr Pumin Zhang and Dr Guojun Lu at Baylor College of Medicine (Houston, TX, USA) and Beijing Proteome Research Center (Beijing, China) for providing us the plasmids.

\section{References}

1. Blackburn EH: Switching and signaling at the telomere. Cell 106: 661-673, 2001.

2. Chiodi I and Mondello C: Telomere and telomerase stability in human diseases and cancer. Front Biosci (Landmark Ed) 21: 203-224, 2016.

3. Shay JW and Wright WE: Senescence and immortalization: Role of telomeres and telomerase. Carcinogenesis 26: 867-874, 2005. 
4. Verdun RE and Karlseder J: Replication and protection of telomeres. Nature 447: 924-931, 2007.

5. Zhang N, Li J, Zhong X, An X and Hou J: Reversible immortalization of sheep fetal fibroblast cells by tetracycline-inducible expression of human telomerase reverse transcriptase. Biotechnol Lett 38: 1261-1268, 2016.

6. Wieser M, Stadler G, Jennings P, Streubel B, Pfaller W, Ambros P, Riedl C, Katinger H, Grillari J and Grillari-Voglauer R: hTERT alone immortalizes epithelial cells of renal proximal tubules without changing their functional characteristics. Am J Physiol Renal Physiol 295: F1365-F1375, 2008.

7. Kapanadze B, Morris E, Smith E and Trojanowska M: Establishment and characterization of scleroderma fibroblast clonal cell lines by introduction of the hTERT gene. J Cell Mol Med 14: 1156-1165, 2010.

8. Gu T, Wang X, Wang X, Wang W, Liu Y, Zhang B, Shi Y, Zhang Z, Sun Q, Xue T, et al: The value of detecting telomerase activity on early diagnosis of lung cancer. Zhongguo Fei Ai Za Zhi 4: 37-40, 2001 (In Chinese).

9. Cavallo D, Casadio V, Bravaccini S, Iavicoli S, Pira E, Romano C, Fresegna AM, Maiello R, Ciervo A, Buresti G, et al: Assessment of DNA damage and telomerase activity in exfoliated urinary cells as sensitive and noninvasive biomarkers for early diagnosis of bladder cancer in ex-workers of a rubber tyres industry. Biomed Res Int 2014: 370907, 2014.

10. Glybochko PV,Zezerov EG, Glukhov AI, Alyaev YG, Severin SE, Polyakovsky KA, Varshavsky VA, Severin ES and Vinarov AZ: Telomerase as a tumor marker in diagnosis of prostatic intraepithelial neoplasia and prostate cancer. Prostate 74: 1043-1051, 2014.

11. Harley CB: Telomerase and cancer therapeutics. Nat Rev Cancer 8: 167-179, 2008.

12. Low KC and Tergaonkar V: Telomerase: Central regulator of all of the hallmarks of cancer. Trends Biochem Sci 38: 426-434, 2013.

13. Gordon DJ, Resio B and Pellman D: Causes and consequences of aneuploidy in cancer. Nat Rev Genet 13: 189-203, 2012.

14. Pfau SJ and Amon A: Chromosomal instability and aneuploidy in cancer: From yeast to man. EMBO Rep 13: 515-527, 2012.

15. Holland AJ and Cleveland DW: Losing balance: The origin and impact of aneuploidy in cancer. EMBO Rep 13: 501-514, 2012.

16. Musacchio A and Salmon ED: The spindle-assembly checkpoint in space and time. Nat Rev Mol Cell Biol 8: 379-393, 2007.

17. Fang $X$ and Zhang P: Aneuploidy and tumorigenesis. Semin Cell Dev Biol 22: 595-601, 2011.

18. Sheltzer JM: A transcriptional and metabolic signature of primary aneuploidy is present in chromosomally unstable cancer cells and informs clinical prognosis. Cancer Res 73: 6401-6412, 2013.

19. Dürrbaum M, Kuznetsova AY, Passerini V, Stingele S, Stoehr G and Storchová Z: Unique features of the transcriptional response to model aneuploidy in human cells. BMC Genomics 15: 139, 2014.

20. Beroukhim R, Mermel CH, Porter D, Wei G, Raychaudhuri S, Donovan J, Barretina J, Boehm JS, Dobson J, Urashima M, et al: The landscape of somatic copy-number alteration across human cancers. Nature 463: 899-905, 2010.

21. Munné S, Bahçe M, Sandalinas M, Escudero T, Márquez C, Velilla E, Colls P, Oter M, Alikani M and Cohen J: Differences in chromosome susceptibility to aneuploidy and survival to first trimester. Reprod Biomed Online 8: 81-90, 2004.

22. Williams BR, Prabhu VR, Hunter KE, Glazier CM, Whittaker CA, Housman DE and Amon A: Aneuploidy affects proliferation and spontaneous immortalization in mammalian cells. Science 322: 703-709, 2008

23. Davoli T, Xu AW, Mengwasser KE, Sack LM, Yoon JC, Park PJ and Elledge SJ: Cumulative haploinsufficiency and triplosensitivity drive aneuploidy patterns and shape the cancer genome. Cell 155: 948-962, 2013.

24. Baker DJ and van Deursen JM: Chromosome missegregation causes colon cancer by APC loss of heterozygosity. Cell Cycle 9: 1711-1716, 2010.
25. Schvartzman JM, Sotillo R and Benezra R: Mitotic chromosomal instability and cancer: Mouse modelling of the human disease. Nat Rev Cancer 10: 102-115, 2010.

26. Li M, Fang X, Baker DJ, Guo L, Gao X, Wei Z, Han S, van Deursen JM and Zhang P: The ATM-p53 pathway suppresses aneuploidy-induced tumorigenesis. Proc Natl Acad Sci USA 107: 14188-14193, 2010.

27. Meena JK, Cerutti A, Beichler C, Morita Y, Bruhn C, Kumar M, Kraus JM, Speicher MR, Wang ZQ, Kestler HA, et al: Telomerase abrogates aneuploidy-induced telomere replication stress, senescence and cell depletion. EMBO J 34: 1371-1384, 2015.

28. Gomez DE, Armando RG and Alonso DF: AZT as a telomerase inhibitor. Front Oncol 2: 113, 2012

29. Zhihua Z, Miaomiao S, Jianping Y and Kuisheng C: Research for the influence of telomerase inhibitors on myeloma cell and therapy. Pak J Pharm Sci 27 (Suppl): 1641-1644, 2014.

30. He M, Jiang YY, Zhu M, Wei X, Qin J, Zhang ZY and Li L: Effects of 3'-azido-deoxythymidine on telomerase activity and protein expression of hepatocarcinoma cell line SMMC-7721. Ai Zheng 25: 543-548, 2006 (In Chinese).

31. Souza Sobrinho CP, Gragnani A, Santos ID, Oliveira AF, Lipay MV and Ferreira LM: AZT on telomerase activity and cell proliferation in HS 839.T melanoma cells. Acta Cir Bras 27: 855-860, 2012

32. Brown T, Sigurdson E, Rogatko A and Broccoli D: Telomerase inhibition using azidothymidine in the HT-29 colon cancer cell line. Ann Surg Oncol 10: 910-915, 2003.

33. Stedt H, Samaranayake H, Kurkipuro J, Wirth G, Christiansen LS Vuorio T, Määttä AM, Piškur J and Ylä-Herttuala S: Tomato thymidine kinase-based suicide gene therapy for malignant glioma - an alternative for Herpes Simplex virus-1 thymidine kinase. Cancer Gene Ther 22: 130-137, 2015.

34. Sabokrouh A, Goodarzi MT, Vaisi-Raygani A, Khatami S and Taghizadeh-Jahed M: Effects of treatment with platinum azidothymidine and azidothymidine on telomerase activity and bcl-2 concentration in hepatocellular carcinoma-induced rats. Avicenna J Med Biotechnol 6: 200-209, 2014.

35. Kim NW and Wu F: Advances in quantification and characterization of telomerase activity by the telomeric repeat amplification protocol (TRAP). Nucleic Acids Res 25: 2595-2597, 1997.

36. Junttila MR and Evan GI: p53 - a Jack of all trades but master of none. Nat Rev Cancer 9: 821-829, 2009.

37. Yu Z, Wang H, Zhang L, Tang A, Zhai Q, Wen J, Yao L and Li P: Both p53-PUMA/NOXA-Bax-mitochondrion and p53-p21cip1 pathways are involved in the CDglyTK-mediated tumor cell suppression. Biochem Biophys Res Commun 386: 607-611, 2009.

38. Boveri T: Concerning the origin of malignant tumours by Theodor Boveri. Translated and annotated by Henry Harris. J Cell Sci 121 (Suppl 1): 1-84, 2008.

39. Paulsson K and Johansson B: Trisomy 8 as the sole chromosomal aberration in acute myeloid leukemia and myelodysplastic syndromes. Pathol Biol (Paris) 55: 37-48, 2007.

40. Baek KH, Zaslavsky A, Lynch RC, Britt C, Okada Y, Siarey RJ, Lensch MW, Park IH, Yoon SS, Minami T, et al: Down's syndrome suppression of tumour growth and the role of the calcineurin inhibitor DSCR1. Nature 459: 1126-1130, 2009.

41. Jones L, Wei G, Sevcikova S, Phan V, Jain S, Shieh A, Wong JC, Li M, Dubansky J, Maunakea ML, et al: Gain of MYC underlies recurrent trisomy of the MYC chromosome in acute promyelocytic leukemia. J Exp Med 207: 2581-2594, 2010.

42. Santaguida S and Amon A: Short- and long-term effects of chromosome mis-segregation and aneuploidy. Nat Rev Mol Cell Biol 16: 473-485, 2015.

43. Xie C, Subhash VV, Datta A, Liem N, Tan SH, Yeo MS, Tan WL, Koh V, Yan FL, Wong FY, et al: Melanoma associated antigen (MAGE)-A3 promotes cell proliferation and chemotherapeutic drug resistance in gastric cancer. Cell Oncol (Dordr) 39: 175-186, 2016. 